\title{
Profile Multiple Intelligence Siswa SMA Negeri 5 Kerinci: Linguistic, Interpersonal, Intrapersonal
}

\author{
Iis Sholihat ${ }^{1}$, Hengki Yandri ${ }^{2}$, Dosi Juliawati ${ }^{3}$ \\ 12,3 Institut Agama Islam Negeri Kerinci
}

*Corresponding author, e-mail: hengki@iainkerinci.ac.id

\begin{abstract}
Students' ignorance of the potential they have, especially the intelligence they have, is an obstacle for students to be able to improve their achievements in school. For that, it needs to be revealed multiple intelligence profiles, especially linguistic, interpersonal, and intrapersonal intelligence of students. This research is a type of quantitative research with a descriptive approach. The population in this study was a student of State Junior High School 5 Sungai Penuh that amounted to 145 people and the study sample was taken with the formula Slovin with random sampling cluster sampling technique, so that the number of samples in this study amounted to 107 people. This research instrument uses the Multiple Intelligence Scale that researchers develop themselves, and then the data that has been collected is tabulated and analyzed with descriptive statistics to calculate respondents' scores using ideal scores. The results of this study revealed that students' multiple intelligence profiles related to linguistic intelligence were in the medium category, then the student's interpersonal intelligence was in the low category, and the student's intrapersonal intelligence was in the medium category.
\end{abstract}

Keyword: Multiple Intelligence, Linguistic, Interpersonal, Intrapersonal

\section{Pendahuluan}

Sekolah adalah organisasi atau tempat bekerja sama dalam upaya melakukan pekerjaan yang berkaitan dengan kegiatan pendidikan (Ngalimun, 2017). Kemudian menurut Mahmud (2012) sekolah memiliki dua pengertian yaitu yang pertama adalah lingkungan fisik dengan berbagai peralatan, tempat penyelenggaraan proses pendidikan untuk usia dan standar tertentu dan yang kedua proses kegiatan belajar mengajar.

Situasi sekolah di mana pembelajaran juga mempengaruhi tingkat keberhasilan belajar. Kualitas guru, metode pengajaran, kesesuaian kurikulum dengan kemampuan anak, kondisi fasilitas di sekolah, kondisi ruangan, jumlah siswa di kelas, penerapan peraturan sekolah, semua itu juga mempengaruhi keberhasilan belajar anak (Dalyono, 2009). Salah satu tugas sekolah adalah memberikan pembinaan kepada siswanya. Mereka harus mendapatkan keterampilan dan pengetahuan dari sekolah, selain mengembangkan kepribadiannya sendiri. Membekali siswa dengan keterampilan dan pengetahuan adalah proses belajar mengajar yang dilakukan oleh guru di sekolah dengan menggunakan metode tertentu (Maesaroh, 2013).

Sebagai lembaga pendidikan formal, sekolah yang melahirkan dan berkembang secara efektif dan efisien merupakan lembaga yang wajib memberikan layanan dalam mencerdaskan warga negara. Sekolah diselenggarakan secara formal, hierarkis dan kronologis, sejalan dengan filosofi dan tujuan pendidikan nasional (Hasbullah, 2011). Secara fungsional memiliki banyak peran, antara lain: (a) membantu mempersiapkan siswa menjadi manusia yang memiliki pengetahuan, keterampilan, keterampilan dapat digunakan dalam kehidupan, (b) membantu mempersiapkan siswa agar 
memiliki kemampuan memecahkan masalah, (c) membantu siswa untuk mandiri sesuai dengan tingkat perkembangan dan potensinya (Hamdani, 2011).

Siswa adalah individu yang unik dengan segala ciri yang dimilikinya yang memiliki potensi, minat, bakat dan kreativitas yang semuanya telah dikembangkan menuju kemandirian, sehingga dapat menjalani kehidupan yang lebih efektif. Salah satu kemandirian adalah kemandirian dalam belajar (Elfira, 2013). Berkaitan dengan hal tersebut, Suprihatin (2015) menyampaikan bahwa siswa akan termotivasi untuk belajar bila memiliki motivasi untuk belajar. 1) kemauan yang kuat untuk melakukannya, 2) jumlah waktu yang dihabiskan untuk belajar, 3) kemauan untuk meninggalkan kewajiban atau tugas lainnya, 4) ketekunan dalam mengerjakan tugas.

Secara umum, anak usia Sekolah Menengah Atas (SMA) bisa digolongkan sebagai remaja paruh baya dan usia Sekolah Menengah Atas (SMA) adalah usia remaja pertengahan setelah mereka memasuki tahun-tahun sekolah menengah atas. Remaja paruh baya berkisar dari 15 hingga 18 tahun (Yusuf, 2014). Masa remaja merupakan usia di mana individu-individu menyatu dalam masyarakat dewasa, usia di mana anak-anak tidak merasa berada di bawah level lansia tetapi memiliki perasaan yang sama atau setidak-tidaknya setara. Memasuki masyarakat saat ini memiliki banyak aspek emosional, lebih atau kurang dari pubertas (Ali \& Asrori, 2010).

Tugas perkembangan remaja meliputi: penerimaan kondisi fisik, penerimaan dan pemahaman peran seks orang dewasa, kemampuan membangun hubungan baik dengan anggota kelompok yang berbeda, mencapai kemandirian emosional, mencapai kemandirian ekonomi, dan mengembangkan persepsi. Keterampilan intelektual, pemahaman dan asimilasi nilai-nilai orang dewasa, dan mengembangkan perilaku yang bertanggung jawab secara sosial (Ali \& Asrori, 2010). Remaja juga mengalami perkembangan pesat dalam aspek kecerdasan. Pergeseran intelektual dalam cara berpikir remaja ini memungkinkan mereka tidak hanya untuk berintegrasi ke dalam komunitas orang dewasa, tetapi juga menjadi ciri khas dari semua periode perkembangan (Ali \& Asrori, 2010).

Menurut pendekatan psikometri, kecerdasan dapat dianggap sebagai ciri psikologis yang berbeda satu sama lain. Kecerdasan dapat diperkirakan dan diklasifikasikan berdasarkan tes kecerdasan Intelligence Measuring Personality, Alfred Binet mengatakan kecerdasan adalah kapasitas yang terdiri dari tiga komponen, yaitu (1) kemampuan mengarahkan pikiran atau tindakan, (2) kemampuan mengubah arah pikiran atau tindakan, dan (3) kemampuan untuk mengkritik pikiran dan tindakan seseorang atau mendominasi (Musfiroh, 2014). Menurutnya, kecerdasan merupakan hal yang fungsional sehingga tingkat perkembangan seseorang dapat diamati dan dievaluasi berdasarkan kriteria tertentu. Kecerdasan majemuk adalah istilah yang digunakan oleh Howard Gardner untuk menunjukkan bahwa manusia pada dasarnya cerdas. Teori ini kemudian dikembangkan dan disajikan pada tahun 1983 dalam bukunya Frames of Mind yang telah diterjemahkan ke dalam 12 bahasa (Syarifah, 2019).

Teori Multiple Intelligence yang menyatakan bahwa kecerdasan mencakup delapan kemampuan intelektual. Teori tersebut didasarkan pada premis bahwa kemampuan intelektual yang diukur dengan tes IQ sangat terbatas karena tes IQ hanya menekankan pada kemampuan penalaran (matematika) dan bahasa. Padahal setiap orang memiliki cara unik untuk menyelesaikan masalah yang mereka hadapi. Kecerdasan adalah kemampuan yang dimiliki seseorang untuk melihat suatu 
masalah dan kemudian memecahkan masalah tersebut atau menciptakan sesuatu yang dapat berguna bagi orang lain (Susanto, 2005).

Teori Multiple Intelligence bertujuan untuk mengubah sekolah sehingga suatu saat suatu sekolah dapat menampung setiap siswa dengan berbagai gaya berpikir yang unik (Susanto, 2015). Istilah intelek berarti kekuatan mental yang menyebabkan seseorang memikirkan aktivitas yang berkaitan dengan proses berpikir, atau kapasitas berpikir yang tinggi (Fatimah, 2006).

Adapun ayat Al-Qur'an yang membahas tentang kecerdasan ada di QS Al-Baqarah Ayat 75, artinya: "Apakah kamu masib mengharapkan mereka untuk percaya kepadamu, meskipun sekelompok dari mereka mendengar firman Allah dan kemudian mengubahnya setelah mereka memabaminya dan mereka tabu?" Maksud ayat ini berarti bahwa kecerdasan terkadang digunakan untuk meligitimasi ketidakpercayaan. Padahal, kecerdasan idealnya digunakan untuk memiliki kecerdasan yang lebih tinggi. Ilmuwan yang bijak tidak berhenti pada tingkat kecerdasan tetapi lebih bersinergi dengan kecerdasan yang lebih tinggi.

Selanjutnya berdasarkan hasil wawancara dengan beberapa siswa di SMA Negeri 5 Sungai Penuh diperoleh informasi bahwa siswa SMA Negeri 5 Sungai Penuh belum mengetahui tentang multiple intelligence dan ada siswa yang tidak mengetahui bahwa kecerdasan dapat ditunjukkan dalam banyak hal, baik melalui kata-kata, angka, musik, gambar, aktivitas fisik (keterampilan motorik), atau melalui sarana sosial dan emosional. Ada juga yang belum memanfaatkan kemampuannya dalam berkomunikasi dengan baik dan benar, seterusnya masih ada hubungan antar siswa yang belum baik, hanya memilih teman dengan orang-orang tertentu saja, tidak mau bergaul dengan teman-temannya yang lain (seperti: siswa yang berasal dari jurusan IPA hanya bergaul dengan siswa jurusan IPA saja, begitu juga dengan siswa dari jurusan IPS). Hal ini tentunya akan membuat proses pembelajaran menjadi kurang efektif jika tidak dilakukan dengan cara yang benar, maka informasi tersebut tidak dapat diterjemahkan dengan benar. Jika dibiarkan, hal ini akan menyebabkan pembelajaran dan perkembangan siswa gagal dan juga akan mengakibatkan perkembangan kecerdasan majemuk selama masa remaja tidak tercapai dengan baik.

Dari hasil penelitian terdahulu mengungkapkan bahwa multiple intelligence digunakan untuk menentukan kecerdasan yang dimiliki siswa berdasarkan hasil tes, hasil analisis tes sistem menunjukkan bahwa faktor yang paling berpengaruh dalam menentukan jurusan berdasarkan minat adalah minat siswa, hasil akademik, tes psikologi, dan keinginan orang tua (Ahsan., Santoso., \& Dchlan, (2015). Selanjutnya hasil penelitian mengungkapkan bahwa pembelajaran berdasarkan kecerdasan majemuk terlaksana sangat baik setelah melaksanakan kegiatan belajar dengan menggunakan kecerdasan majemuk siswa mengalami peningkatan secara klasikal (Purnamasari \& Admoko, 2015).

Profesionalitas guru dalam menjalankan tugasnya sebagai pendidik sangat penting dan semakin guru mampu menunjukkan kinerjanya dengan baik maka siswa akan dapat merasakan manfaatnya dari pelayanan guru. Guru BK merupakan salah satu guru yang dapat membantu permasalahan remaja di sekolah. Kehadiran bimbingan dan konseling di sekolah digunakan sebagai wadah untuk membantu siswa mandiri agar siswa dapat berkembang dan memenuhi tugas perkembangannya (Netrawati et.al, 2018). Harusnya guru BK harus berperan dan bertugas membantu siswa dalam mengembangkan tugas perkembangan dari aspek multiple intelligence siswa. 
Pendidik dalam pembinaan dan konseling memegang peranan penting dalam mengembangkan kecerdasan majemuk siswa pada masa remaja.

Dari paparan data dan hasil kajian teoritis yang telah dilakukan, maka peneliti merasa sangat perlu mengungkap profil multiple intelligence siswa SMA Negeri 5 Sungai Penuh pada bidang Linguistic, Interpersonal, Intrapersonal.

\section{Metode}

Pada penelitian ini, peneliti menggunakan metode kuantitatif pendekatan deskriptif dengan tujuan untuk mendeskripsikan data hasil penelitian apa adanya tanpa pemberian perlakuan sedikit pun. Populasi dalam penelitian ini yaitu siswa Sekolah Menengah Pertama Negeri 5 Sungai Penuh yang berjumlah 145 orang, kemudian guna untuk penelitian ini maka perlu diambil sampel penelitian dengan rumus Slovin dengan teknik pengambilan sampel cluster random sampling. Setelah dilakukan perihitungan dengan rumus Slovin, maka jumlah sampel bisa dilihat pada tabel berikut:

Tabel 1. Sampel Penelitian

\begin{tabular}{ccccc}
\hline No & Kelas & Jumlah & Perhitungan & Sampel \\
\hline $\mathbf{1}$ & X & 43 & $43 / 145 \times 107=31,73$ & 32 \\
$\mathbf{2}$ & XI & 47 & $47 / 145 \times 107=34,68$ & 35 \\
$\mathbf{3}$ & XII & 55 & $55 / 145 \times 107=40,58$ & 40 \\
& Jumlah populasi & $\mathbf{1 4 5}$ & Jumlah Sampel & $\mathbf{1 0 7}$ \\
\hline
\end{tabular}

Data dalam penelitian ini dikumpulkan menggunakan Skala Multiple Intelligence (SMI) yang peneliti kembangkan sendiri yang bersumber dari (Howard Gardner dalam Syarifah, 2019), namun peneliti memfokuskan pada pengungkapan kecerdasan linguistic, interpersonal, intrapersonal. Dalam SMI ini disediakan 4 alternatif jawaban yaitu Selalu diberi skor 4, Sering diberi skor 3, Jarang diberi skor 2 dan Tidak Pernah diberi skor 1. Dari hasil uji reliabilitas internal skala ini memperoleh hasil Cronbach's Alpha sebesar 0.82 .

Prosedur pengambilan data yang dilakukan peneliti yaitu responden diminta untuk mengisi Skala Multiple Intelligence. Peneliti mengadministrasikan skala tanpa campur tangan/intervensi dari guru atau siapapun. Arahan yang diterima peserta di saat mengisi skala yaitu peserta membaca dengan seksama dan teliti setiap item pernyataan skala, kemudian peserta memilih alternatif jawaban yang telah disediakan sesuai dengan kondisi dirinya. Kegiatan yang melibatkan peserta, antara lain siswa menerima lembar skala yang peneliti sebarkan kepada responden, membaca instruksi, menyetujui untuk memberikan informasi, dan mengisi skala.

Kemudian, data yang telah dikumpulkan ditabulasi dan dianalisis dengan statistik deskriptif untuk menghitung skor responden dengan menggunakan skor ideal (Azwar, 2010).

\section{Hasil dan Diskusi}

Data hasil pengungkapan data tentang kecerdasan linguistic siswa bisa dilihat pada gambar 1 berikut. 


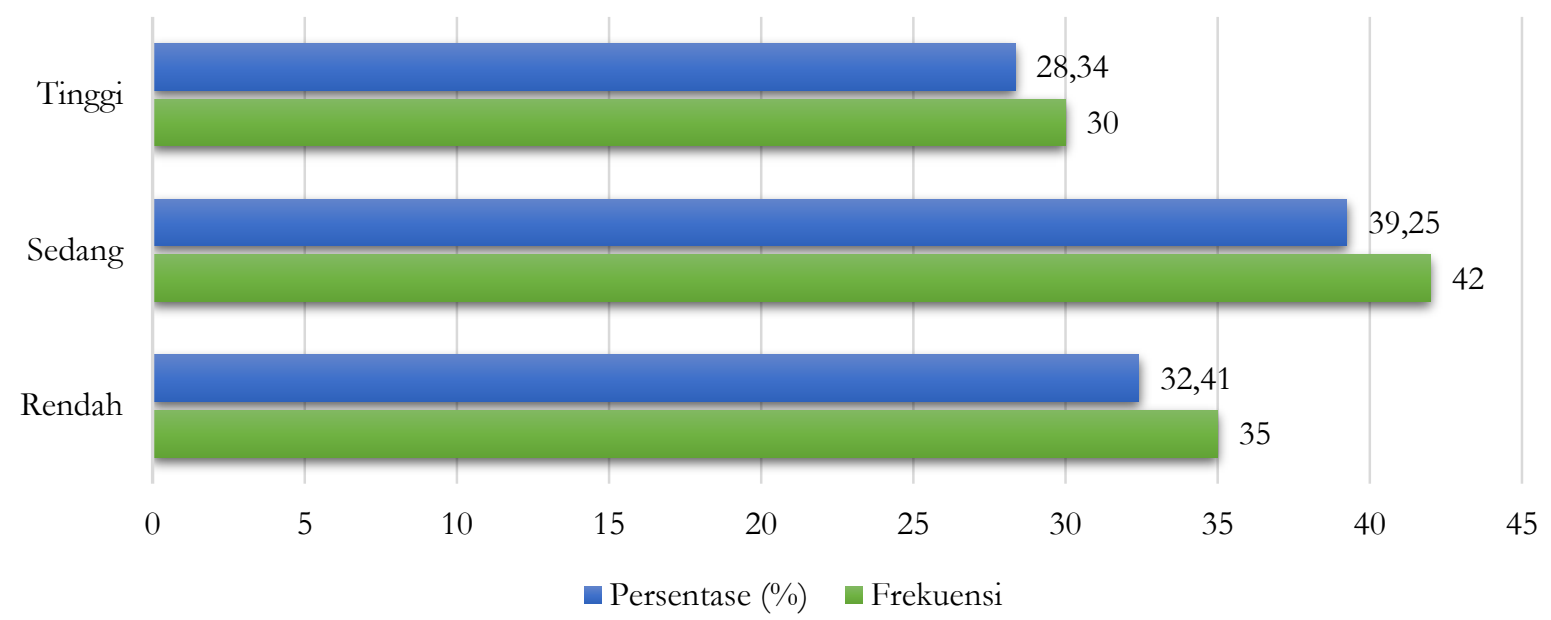

Gambar 1. Distribusi Frekuensi dan Persentase Kecerdasan Linguistic Siswa

Pada gambar 1 di atas, bisa dilihat bahwa rata-rata distribusi frekuensi dan persentase kecerdasan linguistic siswa berada pada kategori sedang yaitu sebesar 39,25\%. Namun demikian, masih ada sekitar 28,34\% siswa dengan tingkat kecerdasan linguistic dengan kategori tinggi dan sebanyak 32,41\% siswa dengan tingkat kecerdasan rendah.

Meskipun hasil persentase tertinggi berada pada kategori sedang. Namun ada beberapa siswa berada pada kategori memiliki kecerdasan linguistic tinggi dengan persentase 28,34\% yaitu sebanyak 30 siswa. Multiple intelligence bidang linguistic yang dimiliki oleh siswa tersebut harus dipertahankan dan disalurkan agar siswa bisa mencapai keberhasilan dalam belajar dan dapat memilih pekerjaan yang tepat sesuai dengan multiple intelligence bidang linguistic yang dimiliki oleh siswa. Selain itu ada siswa yang berada pada kategori memiliki kecerdasan linguistic rendah dengan persentase 32,41\% sebanyak 35 siswa. Terhadap 35 siswa ini, diharapkan kepada guru BK untuk memberikan layanan yang sesuai untuk melatih kecerdasan linguistic, sehingga mereka bisa mengoptimalkan potensi yang mereka miliki untuk meraih sukses.

Menurut teori kecerdasan majemuk seperti yang diungkapkan oleh Thomas Armstrong, (dalam Syarifah, 2019) kecerdasan linguistik atau word smart adalah suatu kemampuan menggunakan kata-kata secara efektif. Dalam kegiatan pembelajaran di sekolah menurut Thomas Armstrong memperlihatkan bahwa kecerdasan linguistik ini mencakup sedikitnya dua pertiga bagian dari interaksi belajar mengajar yang mencakup kegiatan membaca dan menulis. Hasil penelitian Novianti (2013) menunjukkan bahwa permainan kartu bergambar dan kecerdasan linguistic dapat meningkatkan kemampuan membaca permulaan bagi anak-anak. Hal ini menunjukkan bahwa melatih penting dilakukan sejak dini.

Kemudian pengungkapan data tentang kecerdasan interpersonal siswa bisa dilihat pada gambar 2 berikut. 


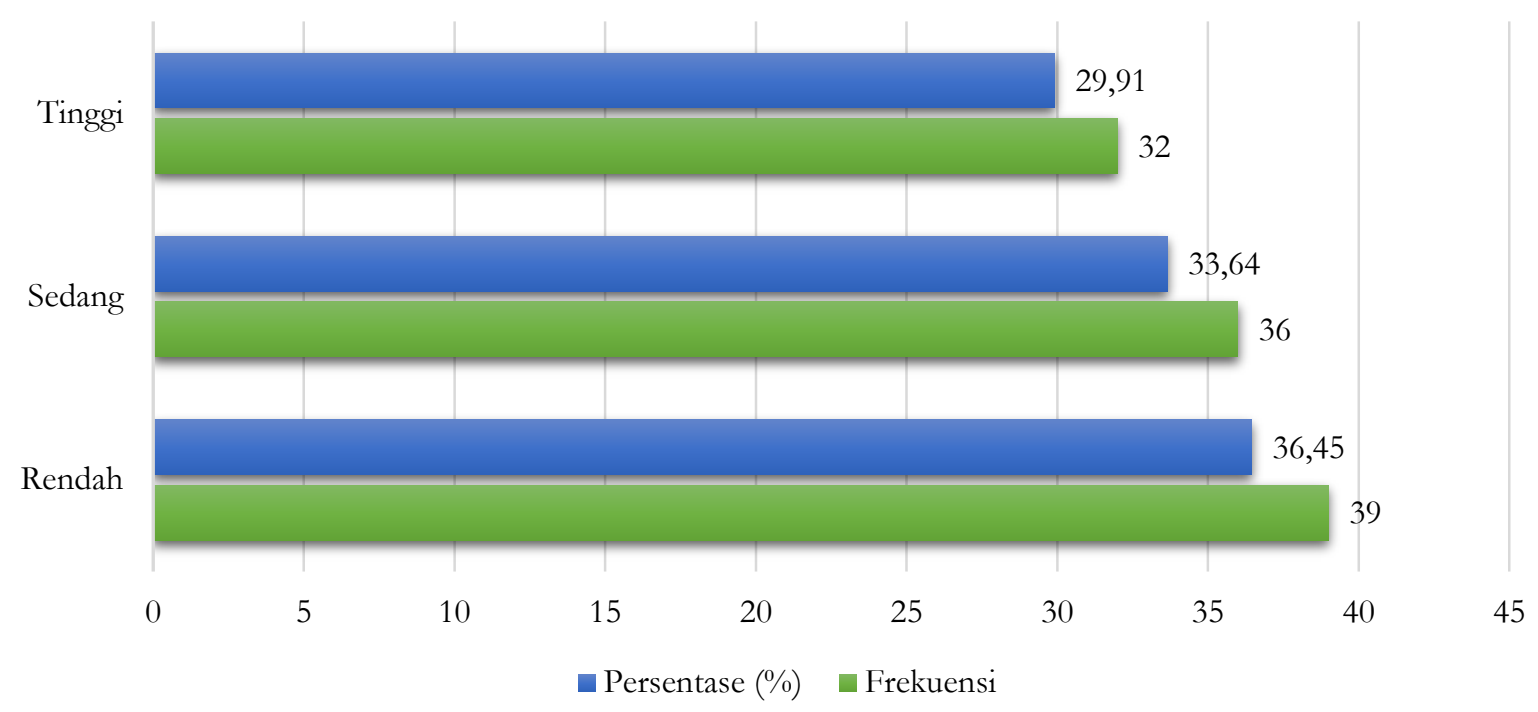

Gambar 2. Distribusi Frekuensi dan Persentase Kecerdasan Interpersonal Siswa

Dilihat pada gambar 2 di atas, terlihat bahwa rata-rata distribusi frekuensi dan persentase kecerdasan interpersonal siswa berada pada kategori rendah yaitu sebesar 36,45\%. Namun demikian, masih ada sekitar 33,64\% siswa dengan tingkat kecerdasan interpersonal dengan kategori sedang dan sebanyak 29,91\% siswa dengan tingkat kecerdasan tinggi.

Persentase tertinggi berada pada kategori rendah yaitu sebesar 36,45\% yaitu sebanyak 39 orang. Hal ini harus menjadi perhatian guru BK di sekolah agar bisa meningkatkan kecerdasan interpersonal siswa di sekolah agar siswa memiliki keterampilan dalam membina hubungan baik dengan orang lain dan lingkungannya. Namun demikian, masih ada siswa yang memiliki kecerdasan interpersonal dengan kategori sedang dan tinggi yang harus dibina dan dipertahankan oleh guru di sekolah sehingga diharapkan bisa menjadi contoh bagi teman-temannya yang lain dalam kehidupan pergaulannya di sekolah maupun di masyarakat.

Kecerdasan interpersonal yaitu kemampuan untuk bisa memahami dan berkomunikasi dengan orang lain, serta mampu membentuk dan menjaga hubungan, dan mengetahui berbagai peran yang terdapat dalam suatu lingkungan sosial (Suarca, et.al, 2005). Hasil penelitian Aprilia (2013) mengungkapkan bahwa ada hubungan negatif antara kecerdasan interpersonal dengan perilaku kenakalan remaja. Untuk itu, sangat penting bagi guru di sekolah membina siswa agar kecerdasan interpersonal siswa bisa menjadi lebih baik lagi dan ditingkatkan.

Seterusnya, data hasil penelitian tentang kecerdasan intrapersonal siswa bisa dilihat pada gambar 3 berikut. 


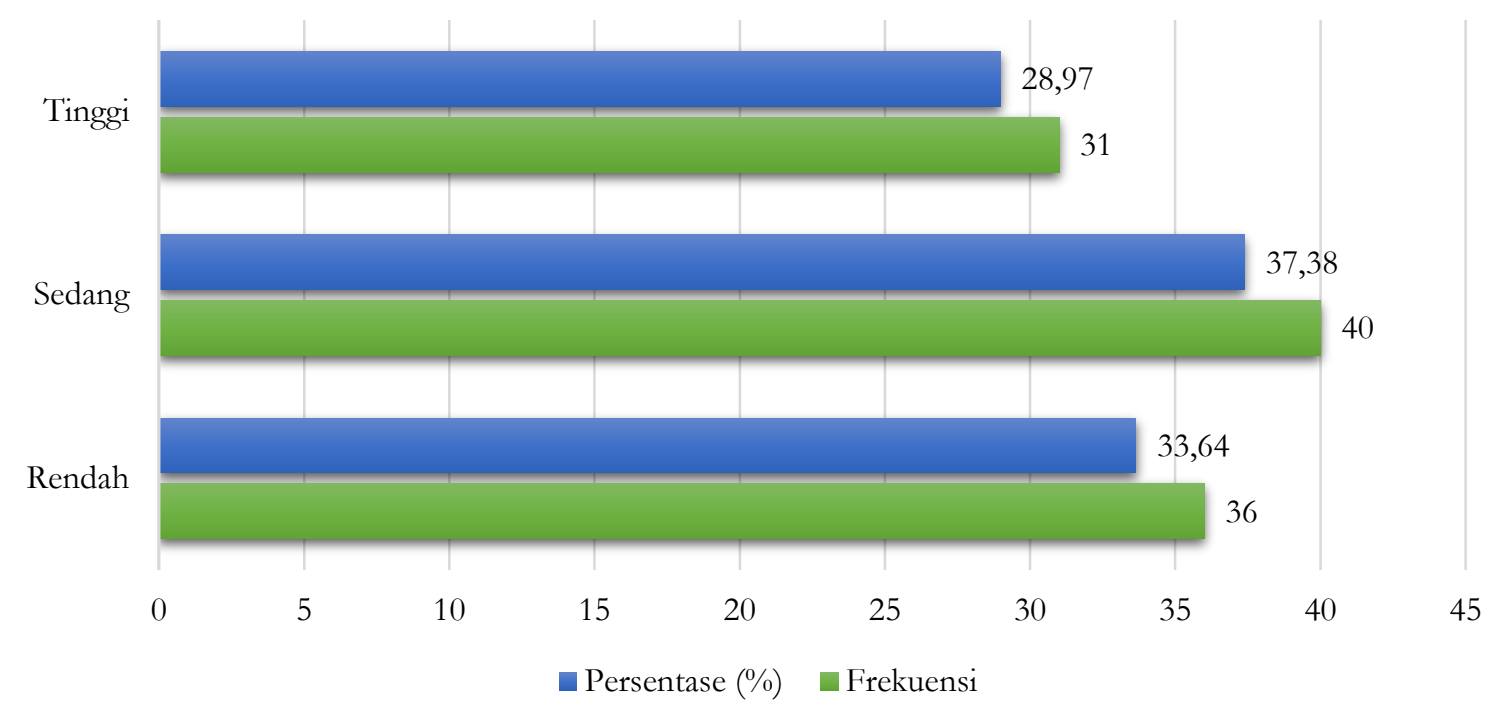

Gambar 3. Distribusi Frekuensi dan Persentase Kecerdasan Intrapersonal Siswa

Pada gambar 3 di atas, bisa dilihat bahwa rata-rata distribusi frekuensi dan persentase kecerdasan intrapersonal siswa berada pada kategori sedang yaitu sebesar 37,38\%. Namun demikian, masih ada sekitar 33,64\% siswa dengan tingkat kecerdasan intrapersonal dengan kategori rendah dan sebanyak $28,97 \%$ siswa dengan tingkat kecerdasan tinggi.

Walaupun rata-rata kecerdasan intrapersonal siswa berada pada kategori sedang yaitu sebesar 37,38\% yaitu sebanyak 40 siswa, namun masih ada sekitar 33,64\% atau sebanyak 36 siswa yang memiliki kecerdasan intrapersonal dengan kategori rendah yang perlu menjadi perhatian sekolah terutama guru BK di sekolah agar memberikan perhatian dengan memberikan layanan bimbingan dan konseling yang sesuai dengan kebutuhan mereka. Karena dari hasil studi terdahulu menunjukkan bahwa ada ada hubungan antara kecerdasan intrapersonal dengan kecerdasan emosi siswa (Maitrianti, 2021), karena kecerdasan emosi yang dimiliki siswa bisa membantu siswa dalam mengontrol kehidupannya ke arah yang lebih baik, sehingga membantu siswa dalam mencapai kesuksesan dalam kehidupannya (Yandri, 2017; Ulandari \& Juliawati, 2019).

\section{Kesimpulan}

Kesimpulan dari penelitian ini mengungkapkan bahwa kecerdasan lingustic siswa berada pada kategori sedang, dan kecerdasan interpersonal siswa berada pada kategori rendah, seterusnya kecerdasan intrapersonal siswa berada pada kategori sedang. Untuk itu, disarankan kepada guru BK di sekolah untuk mengembangkan program BK yang membantu mengembangkan Multiple Intelligence siswa. kemudian kepada peneliti selanjutnya agar mengembangkan penelitian dalam membuat program untuk meningkatkan Multiple Intelligence siswa.

\section{Ucapan Terima Kasih}

Ucapan terima kasih saya sampaikan kepada Bapak Hengki Yandri, M.Pd., Kons yang telah membimbing saya hingga artikel ini bisa diselesaikan dengan baik. Kemudian kepada Bapak Farid 
Imam Kholidin, M.Pd., dan Bapak Agung Tri Prasetia, M.Pd., yang telah bersedia meluangkan waktu memvalidasi Skala Multiple Intelligence yang saya kembangkan. Seterusnya kepada Ibu Dosi Juliawati, M.Pd., Kons., yang telah bersedia memberikan masukan terhadap perbaikan artikel ini. Selanjutnya kepada Kepala SMA Negeri 5 Sungai Penuh yang telah mengizinkan saya untuk melakukan penelitian dan kepada seluruh responden yang telah bersedia mengisi Skala Multiple Intelligence.

\section{Referensi}

Ahsan, M., Santoso, P. B., \& Dachlan, H. S. (2015). Multiple Intelligence Menentukan Jurusan di SMA Menggunakan Teknik Multi-Attribute Decision Making. Jurnal EECCIS, 9(1), 25-30.

Ali, M \& Asrori, M. (2010). Psikologi Remaja, Jakarta: PT Bumi Aksara

Aprilia, F. (2013). Hubungan Antara Kecerdasan Interpersonal dengan Perilaku Kenakalan Remaja pada Siswa SMA N 1 Grobogan. Journal of Social and Industrial Psychology, 2(1).

Dalyono, M. (2009). Psikologi Pendidikan. Jakarta: Rineka Cipta.

Elfira, N. (2013). Peningkatan kemandirian belajar siswa melalui layanan bimbingan kelompok. Konselor, 2(1).

Fatimah, E. (2006). Psikologi Perkembangan. Bandung: CV Pustaka Setia.

Hamdani. (2011). Dasar-Dasar Kependidikan. Bandung: Pustaka Setia.

Hasbullah. (2011). Dasar-Dasar Ilmu Pendidikan. Jakarta: Rajawali Pers.

Maesaroh, S. (2013). Peranan metode pembelajaran terhadap minat dan prestasi belajar pendidikan agama Islam. Jurnal kependidikan, 1(1), 150-168.

Mahmud. (2012). Sosiologi Pendidikan. Bandung: CV Pustaka Setia.

Maitrianti, C. (2021). Hubungan antara kecerdasan intrapersonal dengan kecerdasan emosional. Jurnal MUD ARRISUN A: Media Kajian Pendidikan Agama Islam, 11(2), 291-305.

Musfiroh, T. (2014). Hakikat Kecerdasan Majemuk (Multiple Intelligences). Modul Perkuliahan pdf, Universitas Terbuka.

Netrawati, N., Khairani, K., \& Karneli, Y. (2018). Upaya guru BK untuk mengentaskan masalahmasalah perkembangan remaja dengan pendekatan konseling analisis transaksional. ISLAMIC COUNSELING: Jurnal Bimbingan Dan Konseling Islam, 2(1), 79-90.

Ngalimun. (2017). Kapita Selekta Pendidikan. Yogyakarta: Parama Ilmu.

Novianti, R. (2013). Pengaruh Permainan Kartu Bergambar dan Kecerdasan Linguistik Terhadap Kemampuan Membaca Permulaan. Jurnal Pendidikan Usia Dini, 7(2), 264-275.

Purnamasari, W. S., \& Setyo, A. (2015). Penerapan Pembelajaran Berdasarkan Teori Kecerdasan Majemuk untuk Meningkatkan Hasil Belajar Siswa SMA Kartika Wijaya Surabaya pada Materi Fluida Statis. Jurnal Inovasi Pendidikan Fisika, 4(2), 98-101.

Suarca, K., Soetjiningsih, S., \& Ardjana, I. E. (2016). Kecerdasan majemuk pada anak. Sari Pediatri, 7(2), 85-92.

Suprihatin, S. (2015). Upaya guru dalam meningkatkan motivasi belajar siswa. Jurnal Pendidikan Ekonomi UM Metro, 3(1), 73-82. 
Susanto, H. (2005). Penerapan multiple intelligences dalam sistem pembelajaran. Jurnal Pendidikan Penabur, 4(4), 67-75.

Syarifah, S. (2019). Konsep Kecerdasan Majemuk Howard Gardner. Sustainable, 2(2), 176-197.

Ulandari, Y., \& Juliawati, D. (2019). Pemanfaatan layanan bimbingan kelompok untuk meningkatkan kecerdasan emosi siswa. Indonesian Journal of Counseling and Development, 1(1), 1 8.

Yandri, H. (2017). Efektivitas dirasah pengembangan diri melalui pelayanan konseling dalam membentuk kecerdasan emosi mahasantri Ma'had Al Jami'ah IAIN Kerinci. Tarbawi: Jurnal Ilmu Pendidikan, 13(1), 1-10.

Yusuf, S. (2014). Psikologi Perkembangan Anak dan Remaja. Bandung: PT Remaja Rosdakarya. 